NUREC/CR-0128

SAND 78-0337

RT

SHOCK AND VIBRATION ENVIRONMENTS

FOR A IARGE SHIPPING CONTAINER

DURING TRUCK TRANSPORT (PAKT II)

Clifford F. Magriuson

Maruscript Submitced: February 13,1978
Date Published: May 1978

Sandia Laboratories

Albuquerque, New Nexico 87185

operated by

Sandia Corporation

for the

U.S. Department of Energy

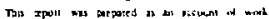

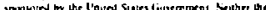

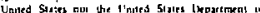

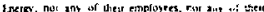

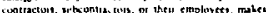
2n

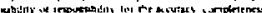

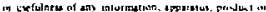

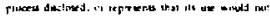

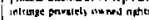

Prepared for

Division of Safeguards, Fuel Cycle and Environmental Research Office of Nuclear Regulatory Research

U.S. Nuclear Regulatory Commission Washington, DC 20555

Under Interagency Agreement DOE 40-550-75

NRC FIN No. A-1049-6 


\begin{abstract}
The purpose of this study was to obtain vibration and shock data during truck shipment of heavy cargo. These data vere for use in determining any crends of vibration and shock environments with increased cargo weight. The new data were obtained on a "piggyback" basis during truck traneport of $249100 \mathrm{~N}(56,000-$ pound) cargo which consisted of a spent fuel container and its supporting structuie. The truck was driven from Mercury, Nevada, to Albuquerque, New Kexico. The routea traveled were US 95 from Mercury, Nevada, to Las Vegas, Nevad.; US 93 from Las Vegas to Kingman, Arizona, and I-40/US 66 from Kingman to Albuquerque, New Merico. Speeds varied from very 6 low to $88 \mathrm{~km} / \mathrm{hr}$ (55 nph). A comparison of data from aimilar experiments with cargo weights varying from no-losd to this load shows that the zero-to-peak acceleration amplitude levels of vibration are highest when trucks carry relatively light loads. This is true for the longitudinal and vertical axes of the vehicles in most frequency bands and for the tranoverse axis above $700 \mathrm{~Hz}$. The shock response acceleration amplitudes for heavier cargo weights were less severe above $3 \mathrm{~Hz}$ in the vertical axis and higher between 8 and $20 \mathrm{~Hz}$ in the transverse axis. The highest acceleration amplitude of shock response in the longitudinal axis below about $20 \mathrm{~Hz}$ was produced in a trailer having a spring suspension system and carrying the $249100 \mathrm{~N}$ ( 56,000 pounds) $100 \mathrm{~d}$.
\end{abstract}




\section{CONTENTS}

$\begin{array}{lc}\text { Summary } & \text { Page } \\ \text { Introdtection. } & 11 \\ \text { Test Description } & 12 \\ \text { Test Procedure } & 12 \\ \text { Highway Description } & 13 \\ \text { Shipping Configuration } & 14 \\ \text { Instrumentation } & 15 \\ \text { Iest Kesults } & 16 \\ \text { Definitions of Dynamic Environments } & 16 \\ \text { Explanation of Data } & 17 \\ \text { Data Reduction } & 17 \\ \text { Truck Data } & 18 \\ \text { Comparison af Truck Data } & 24 \\ \text { Vibration } & 24 \\ \text { Superimposed Shock, Longitudinal Axis } & 27 \\ \text { Superimposed Shock, Transverse Axis } & 29 \\ \text { Superimposed Shock, Vertical Axis } & 30 \\ \text { Single-Pulse Representation of Superimposed Shock } & 31 \\ \text { References } & 33\end{array}$




\section{FIGURES}

1 Shipping Configuration of Trailer, Container, and Data Acquisition Systen

2 Left Side Accelerometer Placement

3 Superimposed Shock Response Spectra

$3 \%$ Damping, Longitudinal Axis

4 Superimposed Shock Response Spectra, 3\% Damping, Transvirse Axis

5 Superimposed Shock Response Spectra, 3\% Damping, Vertical Axis

- Comparison of Truck Vibration Data, Longitudinal Axis

7 Comparison of Truck Vibration Data, Transverse Axis

8 Comparison of Truck Vibration Data, Vertical Axis

Data $3 \%$ Damping, Longitudinal Axis

11 Comparison of Response Spectra From Truck Data $3 \%$ Lamping, Vertical Axis

TABLES

Table

I Truck Vibration, $249100 \mathrm{~N}(56,000$-pound)

Cargo

II Truck Shock Represented by Single halfSine Pulses

III Truck Vibration Comparisol, Zero-to-Peak Amplitude Levels

IV Comparison of Truck Shock Represented by Single Half-Sine PuIses 
SUMAARY

This report consains descriptions of shock and vibration environments thich were measured during truck shipwent of a $249100 \mathrm{~N}$ (56,000-pouno) container mounted on a three-axle trailer which was pulled by a tanjem axle tractor from Mercury, Nevada, to Albuquerque, New Mexico. This report also presents cmparisono of shock and vibration environments for different cargo weights for wich data are available.

The following vibration data from tests show the highest level of input vibration to cargo weighing $249100 \mathrm{~N}(56,000$ pound $\mathrm{s})$ :

\begin{tabular}{lcc}
\multicolumn{1}{c}{ Axis } & $\begin{array}{c}\text { Zero-to-Peak } \\
\text { Acceleration } \\
(\mathrm{g})\end{array}$ & $\begin{array}{c}\text { Frequency } \\
\text { Range } \\
(\mathrm{Hz})\end{array}$ \\
\cline { 2 - 3 } & 0.27 & $0-1900$ \\
Longitudingl & 0.19 & $0-1900$ \\
Transverse & 0.52 & $0-1906$
\end{tabular}

Comparison of vibration data from te日ta show that for cargo weighing more than $133400 \mathrm{~N}(30,000$ pounds)s there is little difference in the vibration amplitudes when the trailers are equipped with air or spring suspension eystems.

The following simple half-sine pulses conservatively represent the maximum expected severities of shock wich is superimposed on and mixed with vibration when the cargo weighs $249100 \mathrm{~N}(56,000$ pounds).

\begin{tabular}{|c|c|c|}
\hline Axis & $\begin{array}{c}\begin{array}{c}\text { Peak } \\
\text { Acceleration } \\
(\mathrm{g}) \\
\end{array} \\
\end{array}$ & $\begin{array}{l}\text { Pulae } \\
\text { Duration } \\
\text { (ms) } \\
\end{array}$ \\
\hline $\begin{array}{l}\text { Longitudinal } \\
\text { Tranaverae } \\
\text { Vertical }\end{array}$ & $\begin{array}{l}2.2 \\
1.6 \\
2.9\end{array}$ & $\begin{array}{l}83 \\
40 \\
59\end{array}$ \\
\hline
\end{tabular}


Comparioon of shock data fron differint teats show that in the longitudinal axis, increased cargo weight produced higher regponses between 1 and $20 \mathrm{~Hz}$ and lower responses above $80 \mathrm{~Hz}$. In the cransverse axis, the heavier cargo produced higher responses between 8 and $20 \mathrm{~Hz}$ but lower responses in other frequencies. In the vertical axis, the responses were lower for heavier cargo above $3 \mathrm{~Hz}$. 


\title{
SHOCK AND VIBRATION ENVIROMENTS FOR A LARGE SHIPPING CONTAINER DURIHG TRUCK TRANSPORT (PART II)
}

\author{
Introduction
}

The packaging and transport of fissile radioactive materials are regulared by the $v$. S. Nuclear Regulatory Comaission by means of the Code of Federai Regulationg Title 10, Part 71, Appendix A of these regulations specifies the environmental conditions of tranaport that are to be applied to deterwine their effects on packages of radioactive materials. However, Appendix A does not specify numerically the frequencies or amplitudes of vibration and shock enviroments nar does it mention their expected occurrence rate as a function of shipment time and/or mileage. As a result, when evaluating a package for Jicensing applications, assumptions regarding these environments are made by each applicant.

To provide guidance in this area, the U. S. Nuclear Regulatory Comisuion cintracted with Sandia Laboratories to gather and evaluate data regarding the truck and rail shock and the vibration environments normally encountered in transporting large shipping casks. The project is divided into three tasks:

1. Extract, review, and reduce shock and vibration environment definitions curreatly on file in both the DOE/DOD and DOE Transportation Environment Data Banks. Determine the beat, simply scated estimates of envirginents for large shipping containers on trucks and railroad cars.

2. Conjuct dymamic analyses of the shock environment experienced by cargo in rail switching and coupling to identify the dependence of the shock environment on heavy cargo weights and on shock attenuation couplers. 
The results are to be uned to refine further the shock ioad description. Existing athewatical modele of freight cars will be altered to study these special concerns.

3. Idestify, during the performance of Taska 1 and 2 , the need for additional data. The ceoto wich are neceagary to obtain the dat $a$ are to be planned. Actual meagurements will be obtained on "pigsyback" basis.

Tasks 1 and 2 were reported in Reference 1. Data obtained during transport of a $195700 \mathrm{~N}(44,000$-pound) concainer were reported in Reference 2. The present investigation is concerned with truck cargo weighing $249100 \mathrm{~N}$ (56,000 pounds).

All data reported herein were aken in English units. The metric (SI) values presented result from rounded conversions from the English values.

Test Description

This test was conducted to obtain data on the vibration and shock environments experienced during truck shipment of cargo wich was heavier than the cargo shipments on which data were previously obtained (References 1 and 2). Changes, if any, in the environmental levels to which cargo is exposed with increasing total cargo weight were to be identified.

\section{Test Procedure}

In a separate DOE/ECT funded investigation, Sandia Laboratories procured wo representative spent fuel shipping containers for use in a series of fill-scale vehicle-container impact tests. Since the containers had been in service, they required decontamination prior to these planned tests. The decontamination was accomplished at the DDE/ Nevada Test Site at Mercury, Nevada. After decontanination, the containers were moved to Sandia Laboratories, Albuquerque, New Mexico. 
Transportation of the cont iipers from one DOE facility to another provided an excellent opportunity to conduct the teoto reported in Reference 2 and herein on "piggyback" basis.

The shipment routs was detemined by Tri-State Hotor Transit Company through their normal routing procedures. The data measurements were conducted on a sampling basis; therefore, Sandia personnel conducted a pretest route survey by driving from Albuquexque to Mercury to identify potential shock-producing road characteriatics (bridges, railroad crossings, cattle guards) as well as to identify different road types (rough and smooth blacktop, rough and smooth cancrete, and divided and undivided highways). The locations of various road segments over which data were to be ampled were established; and data were taken at these locations during the shipment. During the test, the drivera of the Tri-State tractor and the Sandia personnel following in another vehicle were in radio communication so that the locations of the road features to be included in the data samples were identified by personnel in both vehicles. The data sampling system was operated remoteij $\mathrm{t}_{j}$ Sandia personnel when the desired sampling points were encountered.

\section{Highway Description}

The routes traveled were US 95 from Mercury, Nevada, to Las Vegas, Nevada; US 93 from I.as Vegas, Nevada, to Kingman, Arizona; and I-40/US 66 from Kingman, Arizona to Albuquerque, New Mexico.

The highway from Mercury to Las Vegas was four lane, divided, smooth blacktop through flat country. The highway from Las Vegas to Hoover Dam and through urban and semi-urban communities included three-, four-, and six-lane divided blacktop roads. The highway from east of Hoover Dam to Kingman, Arizona, was relatively rough, two-lane blacktop, undivided highway over rolling countryside. The segment from Kingman, Arizona to Seligman, Arizona was gmooth, two-lane, undivided blacktop over very level country. From Ashford, Arizona, to Albuquerque, Hew Mexico, the highway segments over thich data were 
taken were four-1awe, divided highways made from boti, concrete and blacktop. The final segments were through mountainous and high degert country.

Data vere also recorded to determine the characteriorica of shock superimposed on and mixed with the vibxation. Two cattle guard crosainge, two railroad crossinga, and five bridges were encounteres. The peed at which these were transversed ranged from $42 \mathrm{~km} / \mathrm{hr}$ (26 mph) to $88 \mathrm{~km} / \mathrm{hr}(55 \mathrm{mph})$.

\section{Shipping Configuration}

The trailer on which the container was mounted (Figure 1) was menufactured by Fruehauf. It was 12.2 metros ( $40 \mathrm{feet}$ ) Iong and was equipped with a three-axle, spring subpension system. The tractor was a White Freightline: equipped with tandem axles with a "velvet-ride" suspension system.

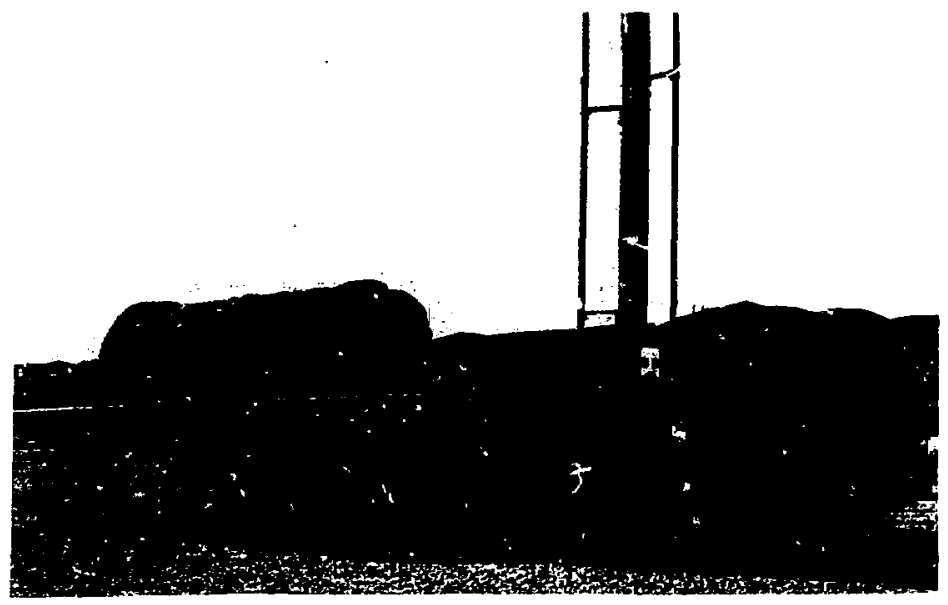

Figure 1. Shinping Configuration of Trailer, Container, anci Data Acquisition System 
The container was oupportes at each end by structures wich were fastened to structural members of the trailer. It was wanufacturad by Knajp Mills, Incorporated, and uas previously uwhed by the General Electric Conpany. The weight of the cask, aupport structure, and trailer was $305100 \mathrm{~N}(58,600$ pounde). The total weight of the shipment, including the tractor, way $378700 \mathrm{~N}(85,140$ pounds,.

\section{Inst rumentation}

The instrumentation consisted of accelerometers with associated cabling, and a daca acquisition system (LAS) which was designed and fabricated at Sandis laboratories. The DAS contained the signal conditioning equiprent and a tape recorder to provide a record of the output fror the trangducers. The DAS could be operated remotely by radio link, oo data sampling was controlled by Sandia persinnel tho were following the truck.

Fourteen data channels were available on the DAS. One channel was used to record the IRIG tiae being zenerated by the DAS. This was done to perwit identification of specifir segmenta on the data tape for data reduction. One data channel was used ts provide coded identification of apecific events. Twelve data channels were used to record the excitation being experienced by the acceleroneters.

Four set 8 of three accelerometers each vere used to measure the environment at each of the major axes (longitudinal, transverse, and vertical) at the structure supporting the container (Figure 2). Three piezoelectric accelerometers and thres piezorebistive acceleroneters were wounted at eech end of the container. Two types of accelerometers were used to provide data over frequencies from $\mathrm{O} \mathrm{Hz}$ to $1900 \mathrm{~Hz}$. The output from these accelerometers was recorded on wagnetic tape after the signal had been conditioned by the DAS. 


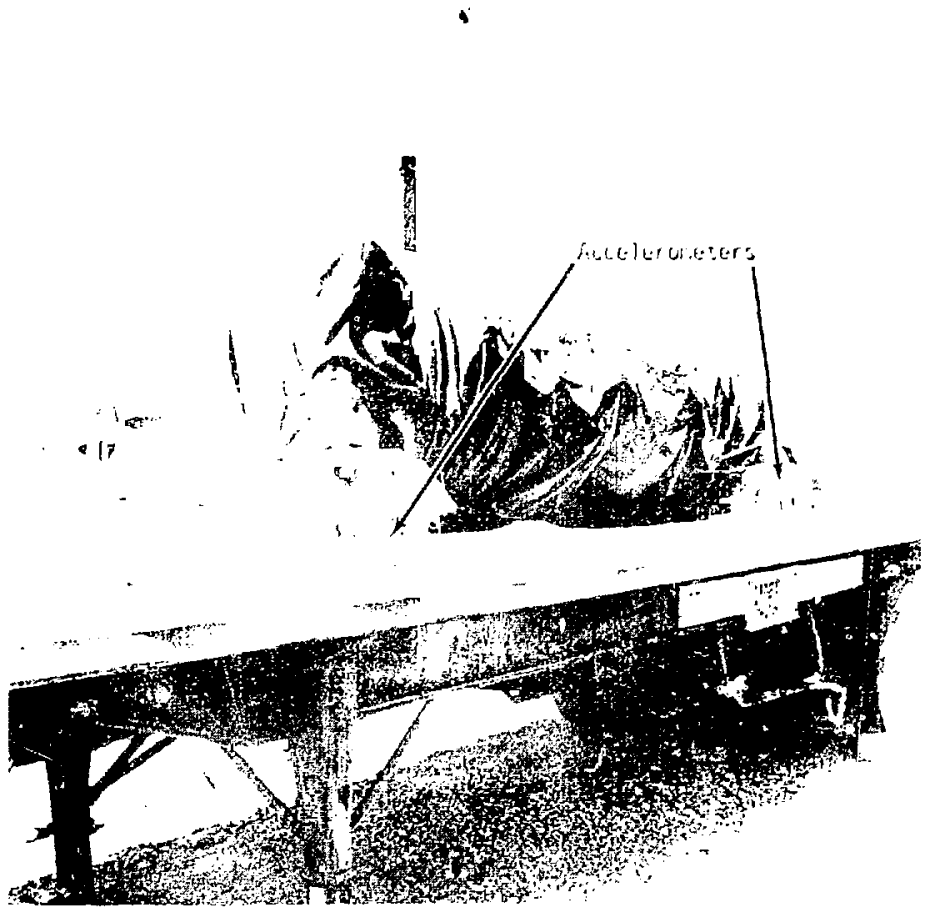

Figire 2. Lert Sidr Accelerometer plasement

Test Results

The environmental descriptions presented in this section summarize the data obtained during tile truck shipment of th? 249 100N $(56,000-$ pound) (argo from Mercury, Nevaria, ro Albuquerque, New Mexico.

\section{Definitions of Dynamic Environments}

Dynamic oxitacions delivered to cargo may be described ar a wixture of vibration, occasional shock superimposed on the vibtation, and isolated shock which occurs in single events such as rail coupling. 


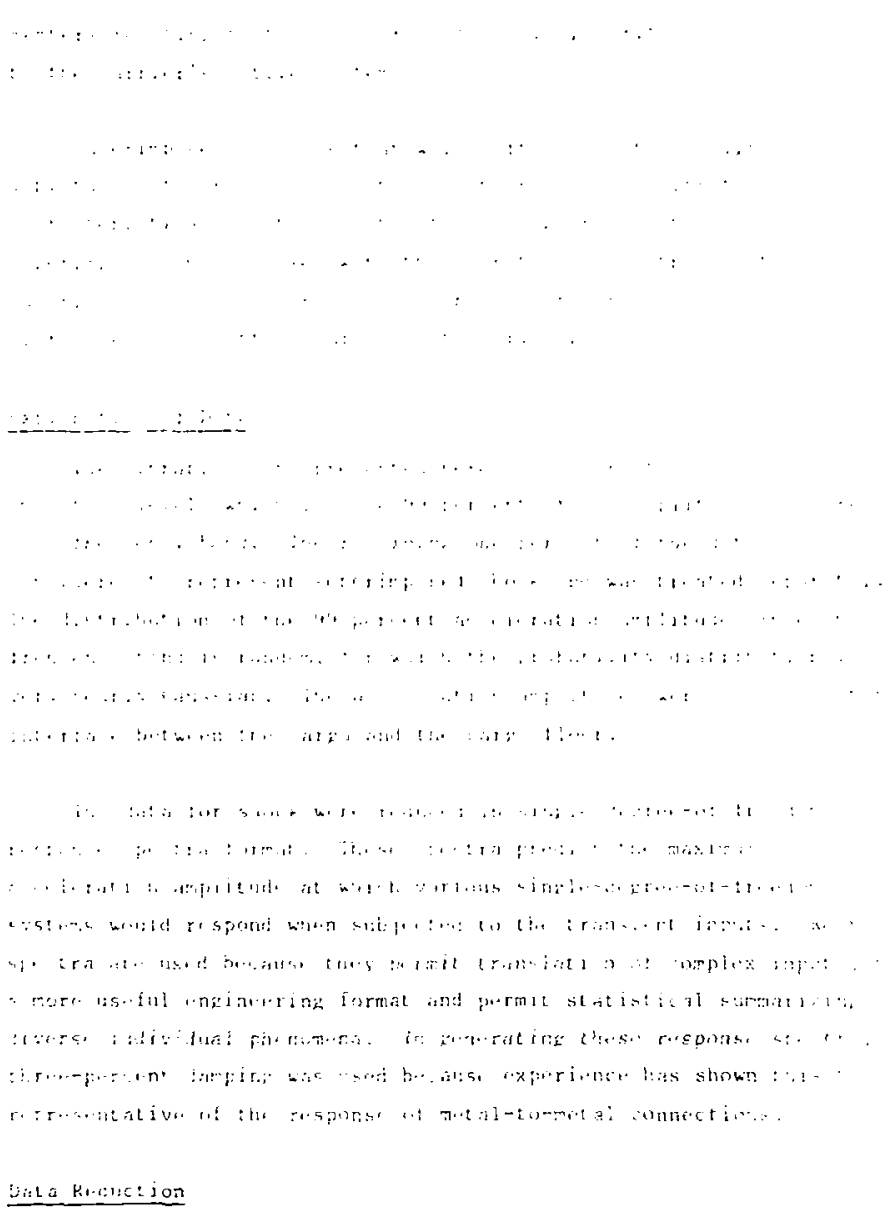

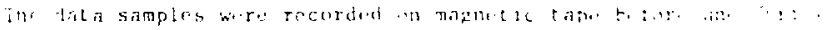

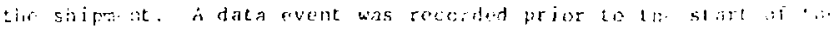

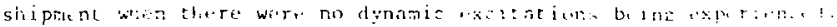


This data event was used to determine the background, electrical "noise" in each chennel. An oscillograph record of the entire data tape was produced in order to allow correlation of bpecific events with the associaced data tape segmeats to be used for data reduction. The events were identified for date reduction as either vibration or shock. vibration data were reduced by the tata reduction program VIBfan. This program count 6 the number of zero-to-peak acceleration amplitudes in predetermined amplitude ranges in preselected frequency bar.ds. After the VIBRAN records were available, those records in which data were above the "noige" level were selected for combination into a composite record by program VaIL. The VaIL program combines VIBRAN recorda and displays the restlting diatribution of zero-to-peak amplitudes in the same format as the individual VIBRAN records.

The superimposed shock records were reduced in response spectra format. The individual response spectra were than combined by program 2STP. This program produces the mean response spectrum of the spectra being combined, the peak acceleration of all the records combined, and the three standard deviations about the mean level of response of the records which were combined.

\section{Truck Data}

Vibration - The vibration data presented herein are zero-to-peak acceleration amplitude levels which envelop 99 percent of all amplitudes measured in each frequency band. The vibration levels presented are those which define the input to the cargo.

The highest of the 99-percent zero-to-peak accelerations occurred in the vertical axis. These amplitude levels were between $0.19 \mathrm{~g}$ and $0.52 \mathrm{~g}$ from $0 \mathrm{~Hz}$ to $500 \mathrm{~Hz}$ and were at $0.10 \mathrm{~g}$ from $500 \mathrm{~Hz}$ to $1900 \mathrm{~Hz}$.

The highest of the 99-percent zero-to-peak accelerations in the longitudinal axis was $0.27 \mathrm{~g}$, which occurred in the $0-\mathrm{Hz}$ to $5-\mathrm{Hz}$ frequency band. The acceleration amplitude levels were lower in all other frequencies. 
The highest of the 99-percent zero-to-peak occelerations in the transverse axis was $0.19 \mathrm{~g}$, which occurred in the $10-\mathrm{Hz}$ to $20-\mathrm{Hz}$ frequency band. As was the case for the vertical axis, the amplitude levels decreased above $500 \mathrm{~Hz}$. Details of the 99-percent zero-to-peak amplitude levels in each frequency band and each axis are presented in Table I.

TABLE I

Truck Vibration 249 100N (56,000-Pound) Cargo

Input to Cargo ( $\mathrm{B})$; $99 \%$ Level of Zero-to-Peak Amplitude

\begin{tabular}{cccc}
$\begin{array}{c}\text { Frequency } \\
\text { Band (Hz) }\end{array}$ & $\begin{array}{c}\text { Iongitudingl } \\
\text { Axis }\end{array}$ & $\begin{array}{c}\text { Trangverse } \\
\text { Axis }\end{array}$ & $\begin{array}{c}\text { Vertical } \\
\text { Axis }\end{array}$ \\
\cline { 2 - 3 } $0-5$ & 0.27 & 0.10 & 0.52 \\
$5-10$ & 0.14 & 0.07 & 0.27 \\
$10-20$ & 0.19 & 0.19 & 0.37 \\
$20-40$ & 0.10 & 0.07 & 0.19 \\
$40-80$ & 0.10 & 0.10 & 0.37 \\
$80-120$ & 0.07 & 0.10 & 0.37 \\
$120-180$ & 0.07 & 0.10 & 0.52 \\
$180-240$ & 0.05 & 0.10 & 0.52 \\
$240-350$ & 0.07 & 0.14 & 0.52 \\
$350-500$ & 0.05 & 0.07 & 0.37 \\
$500-700$ & 0.05 & 0.02 & 0.10 \\
$700-1000$ & 0.05 & 0.02 & 0.10 \\
$1000-1400$ & 0.14 & 0.05 & 0.10 \\
$1400-1900$ & 0.03 & 0.02 & 0.10
\end{tabular}

Shock -- The shock data presented were obtained during the same test as the truck vibration data but from different specific events. The shock data were obtained frotn measurements taken when the truck encountered railroad crossings, cattle guard crossings, and bridge approaches. The data define the response at the interface between the cargo and the cargo floot. 
The date are presented in ahock response spectra forat. Threepercent damping wa used to produce the reoponse opectra because experience has shown this to be representative of the response of metalco-metal atructures. The data present the results of combining the individual response spectre in each of the wajor axes (longitndinal, trangverge, and vertical). Each plot presents the mean, peak, and three-standard-deviation response spectra.

The vercical axis produced response spectra which were higher in amplitude than the other two axes at all frequencies. All three axes showed high response at approximately $15 \mathrm{~Hz}$, which is the frequency at which tires have the greatest response. At approximately $2.5 \mathrm{~Hz}$, all three axes showed peak response but of lower amplitudes than those at $15 \mathrm{~Hz}$. Near this frequency, suspension systems have the greatest response. The response apectra for al three axes sre shown in Figures 3,4 , and 5 .

Single-Pulse Representation of Shock -- Single-input pulses are a convenient way of approximating complex input shock pulses for evaluating mechanical structures. The single-input pulses pregented were obtained by comparing their response spectra with the response spectra obtained from the test data. The comparison nethod usually irtroduces conservatism because the response spectra from test data are enveloped by the single-pulse response spectra up to the highest frequency of intereat. Several simple pulses can be selected to define an input pulse. In this report, half-sine pulses are used.

The pe. $k$ acceleration of the selected half-sine input pulses for the three-standard-deviation and absolute peak response spectra do aut vary significantly. The peak acceleration of simple pulses which have response spectra that envelop the mean of the combined response spectra for each axis are generally about half the amplitude of the other two spectra for the absolute peaks and three standard deviations for that axia. Table II shows a comparison of the characteristics of single islf-sine puloes for the different levels of response. 


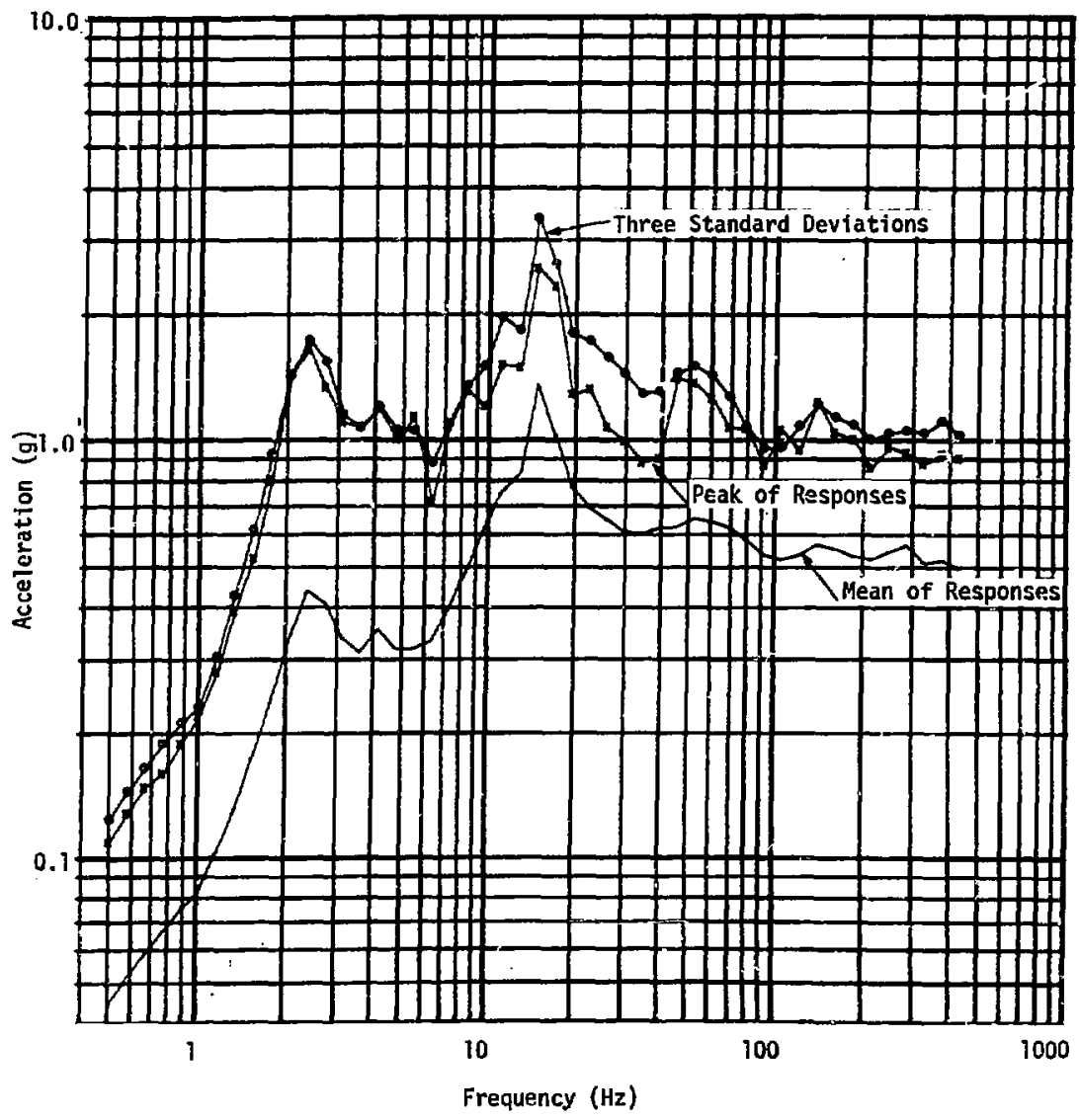

Figure 3. Superimposed Sh zck Response Spectra, 37. Damping, Longitudinal Axis 


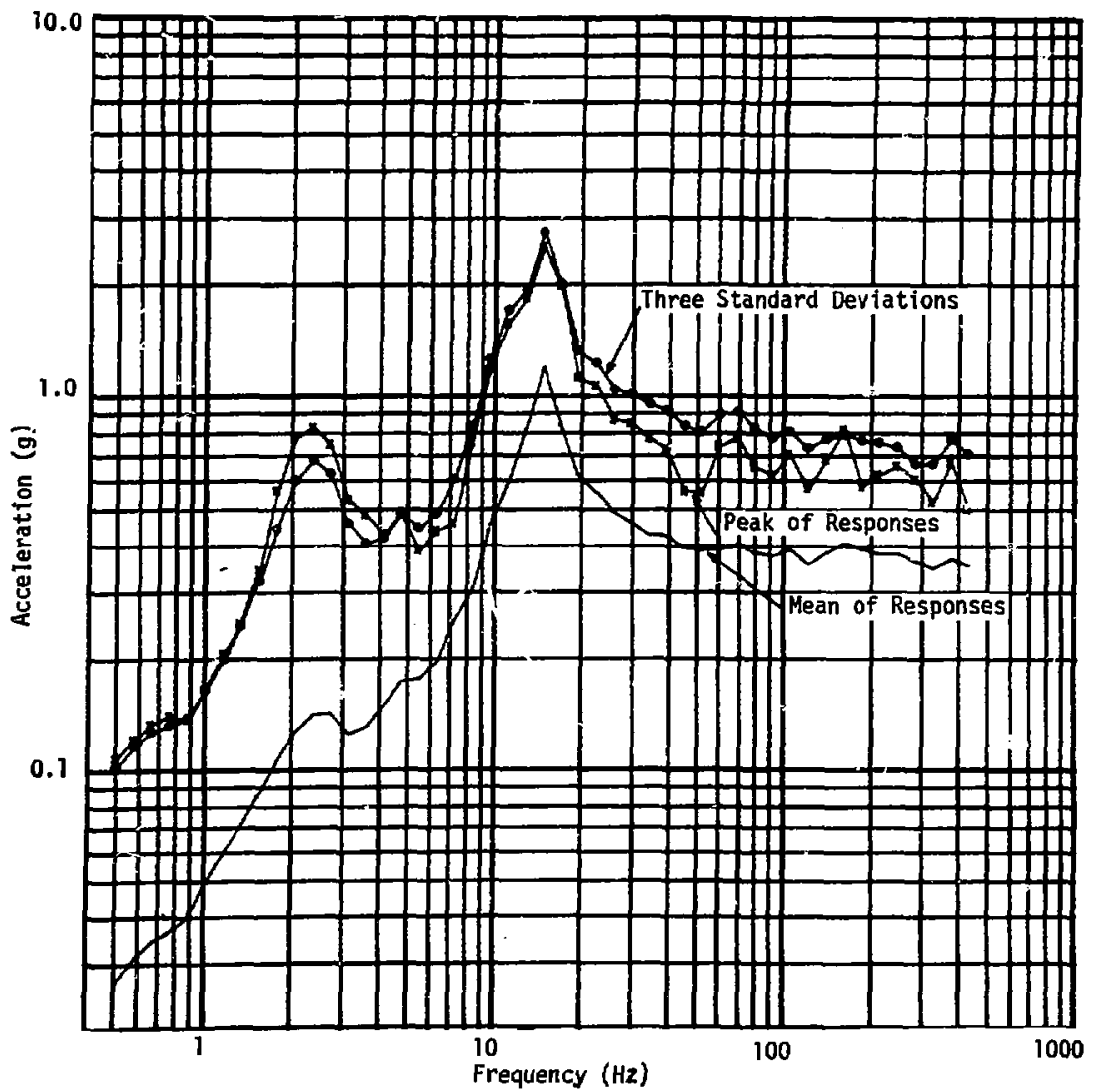

Figure 4. Superimposed Shock Response Spectra,

37 Damping, Tranaverse Ariq 


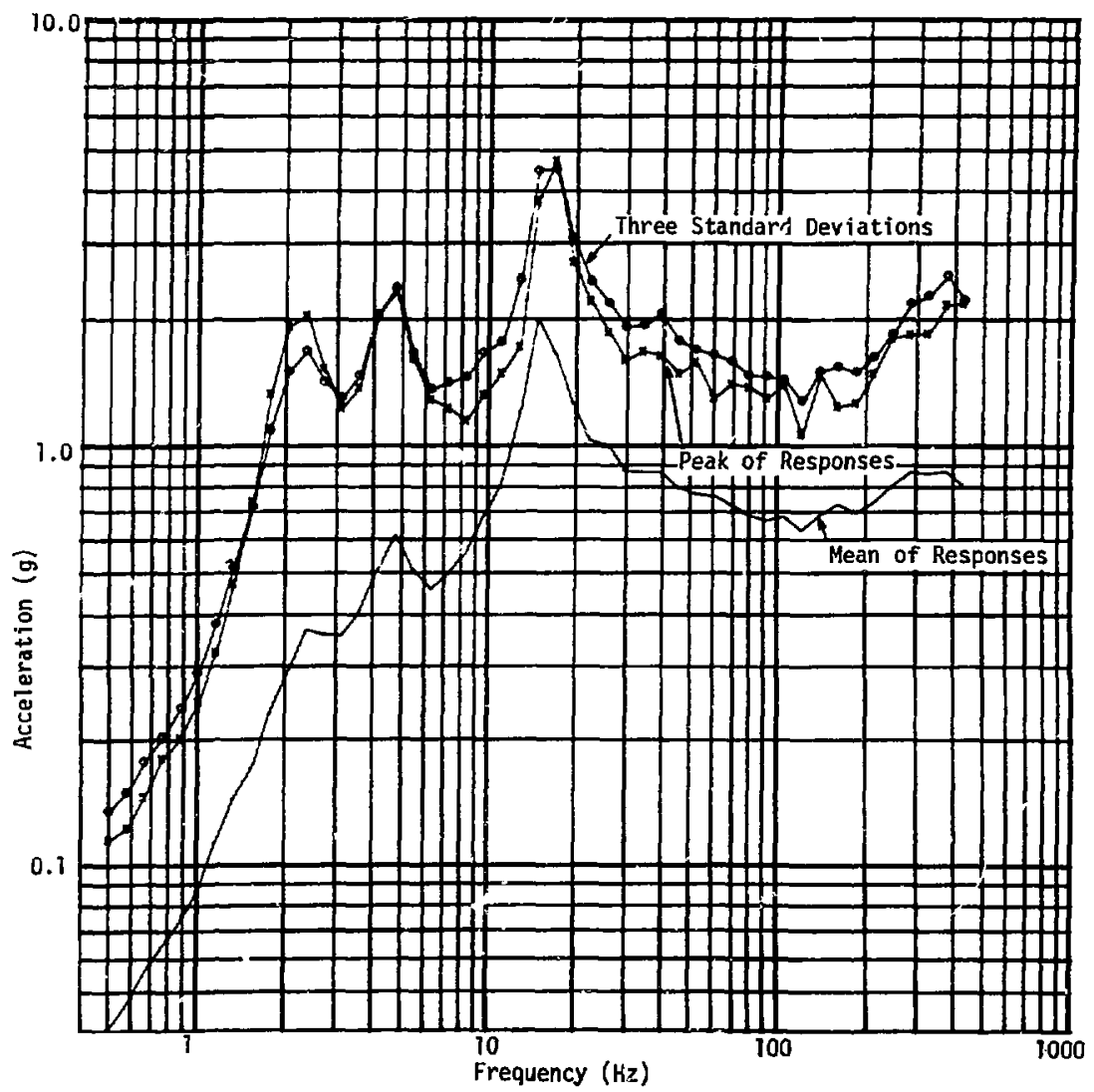

Figure 5. Superimposed Shock Response Spectra, 37 Damping, Vertical Axio 
TABLE II

Truck Shouk Represented by Single Half-Sin: Pulges

\begin{tabular}{|c|c|c|c|}
\hline Axis & $\begin{array}{c}\text { Peak } \\
\text { Accelezation } \\
(\mathrm{g})\end{array}$ & $\begin{array}{c}\text { Pulse } \\
\text { Duration } \\
\text { (me) }\end{array}$ & $\frac{\text { Velocity Change }}{(\text { m/a })(\overline{f E / d})}$ \\
\hline
\end{tabular}

From Response Spectra of Three-Stendsrd-Deviatioss

$\begin{array}{lllll}\text { Longitadinal } & 2.2 & 83 & 1.1 & 3.7 \\ \text { Transverse } & 1.6 & 40 & 0.4 & 1.3 \\ \text { Vertical } & 2.6 & 61 & 1.1 & 3.5\end{array}$

From Response Spectra of Atsolute Zeak Responses

$\begin{array}{lllll}\text { Longitudinal } & 1.8 & 91 & 1.0 & 3.3 \\ \text { Transverse } & 1.3 & 59 & 0.5 & 1.6 \\ \text { Vertical } & 2.9 & 59 & 1.1 & 3.5\end{array}$

From Response Spectra of Hean Responses

$\begin{array}{lllll}\text { Longitudinal } & 0.8 & 50 & 0.2 & 0.8 \\ \text { Transver be } & 0.7 & 37 & 0.2 & 0.5 \\ \text { Vertical } & 1.3 & 37 & 0.3 & 1.0\end{array}$

Comparison of lruck Datg

\section{Vibration}

Comparison of the zero-to-peak vibration amplitude levels ohows that the highest. vibration input occurs when trucks carry relatively light loads. Ihis is particularly true for the longitudinal and vertical sxed in most frequency bands and for the transverse axis in frequencies above $700 \mathrm{~Hz}$. For cargo weighing more than $133400 \mathrm{~N}$ ( 30,000 pound 8$)$, there is little difference in the vibration amplitudes regardleas of the $c$ ppe of suspension systems on the crailers. Table III presents zero-to-pesk vibration amplitude levels for different 
vargo weights. Figures 6,7 , and 8 prescat the same data comparison in graphical for.a. The data cover thlee cargo weights.

\section{TABLE III}

Truck Vibraticn Comparison Zero-to-Peak Amplitude Levcls Input to Cargo $(g) 99 \%$ Lovel of

\begin{tabular}{|c|c|c|c|c|c|c|c|c|c|}
\hline \multirow[b]{3}{*}{$\begin{array}{l}\text { Frequency } \\
\text { band }(\mathrm{Hz})\end{array}$} & \multicolumn{9}{|c|}{ Zero-Lo-Pear Amplitude } \\
\hline & \multicolumn{3}{|c|}{ Long ituénei } & \multicolumn{3}{|c|}{ Transverse } & \multicolumn{3}{|c|}{ Vertical } \\
\hline & (1) & $\begin{array}{l}\text { ixis } \\
\text { (2) }\end{array}$ & (3) & (1) & $\begin{array}{l}\text { Axis } \\
\text { (2) }\end{array}$ & (3) & (1) & $\begin{array}{r}\text { Axis } \\
\text { (2) }\end{array}$ & (s) \\
\hline $0-5$ & 0.10 & 0.14 & 0.27 & 0.10 & 0.14 & 0.10 & 2.00 & 0.27 & 0.52 \\
\hline $5-10$ & 0.08 & 0.19 & 0.14 & 0.06 & 0.19 & 0.07 & 1.04 & 0.19 & 0.27 \\
\hline $10-20$ & 0.84 & 0.27 & 0.19 & 0.15 & 0.27 & 0.19 & 1.68 & 0.27 & 0.37 \\
\hline $20-40$ & 0.51 & 0.10 & 0.10 & 0.24 & 0.27 & 0.07 & 1.20 & 0.27 & 0.19 \\
\hline $40-80$ & $0.3 h$ & 0.14 & 0.10 & 0.42 & 0.14 & 0.10 & 0.50 & c. 52 & 0.37 \\
\hline $60-120$ & 6.24 & 0.07 & 0.07 & 0.27 & 0.10 & 0.10 & 0.87 & 0.52 & 0.37 \\
\hline $120-180$ & 1.23 & 0.07 & 0.07 & 0.21 & 0.10 & 0.10 & 0.63 & 0.52 & 0.52 \\
\hline $180-240$ & 0.87 & 0.05 & 0.05 & 0.12 & 0.10 & 0.10 & 0.87 & 0.52 & 0.52 \\
\hline $240-350$ & 0.24 & 0.05 & 0.07 & 0.15 & 0.10 & 0.14 & 0.63 & 0.52 & 0.52 \\
\hline $350-500$ & 0.24 & 0.05 & 0.05 & 0.15 & 0.05 & 0.07 & 0.42 & 0.14 & 0.37 \\
\hline $500-700$ & 0.87 & 0.04 & 0.05 & 0.15 & 0.04 & 0.02 & 0.87 & 0.07 & 0.10 \\
\hline $700-1000$ & 1.50 & 0.03 & 0.05 & 0.87 & 0.07 & 0.02 & 1.17 & 0.07 & 0.10 \\
\hline $1000-1400$ & 0.67 & 0.01 & 0,14 & 1.17 & 0.04 & 0.05 & 1.17 & 0.05 & 0.10 \\
\hline $1400-1900$ & 0.39 & 0.01 & 0.63 & 0.24 & 0.05 & 0.02 & 0.87 & 0.05 & c. 10 \\
\hline
\end{tabular}

(1) Cargo weight: no load to $133400 \mathrm{~N}(30,000$ pounds $)$. Spring and air suspansion systems (Reference l).

(2) Cargo weight: $195300 \mathrm{~N}(44,000$ pounds). Air suspension system (Refereuce 2 ).

(3) Cargo weight: 249 100N (56,000 pounds). Spring guspension system. 


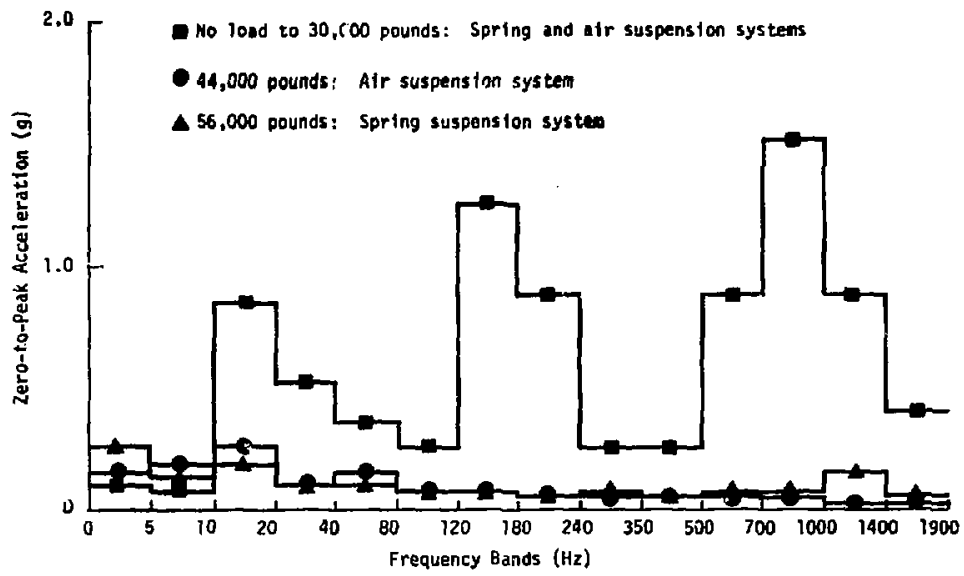

Figure 6. Comparioon of T $\tau^{-1}=k$ Vibration Data, Longitudinal Axis

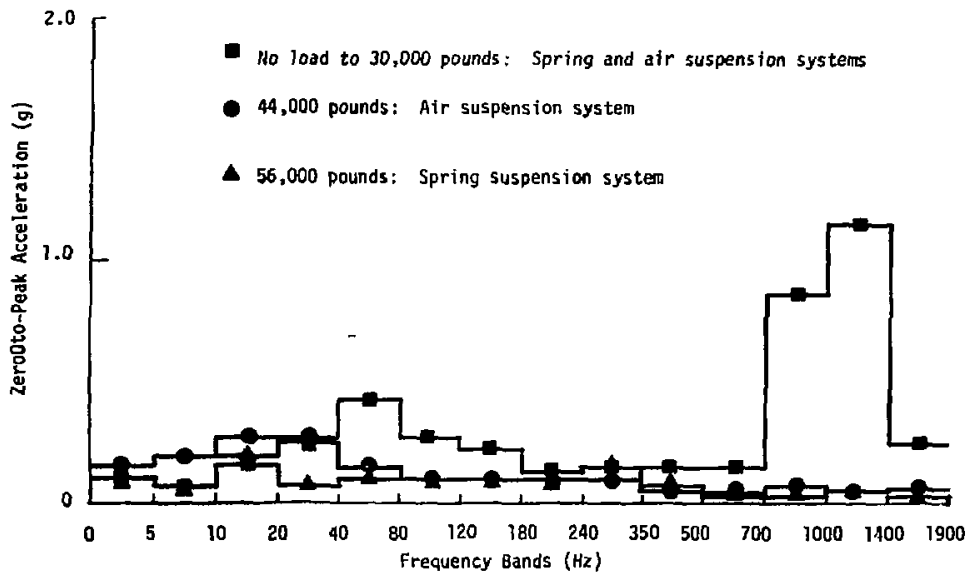

Figure 7. Comparison of Truck Vibration Data, Transveroe Axis 
- No load to 30,000 pounds: Spring and air suspension system

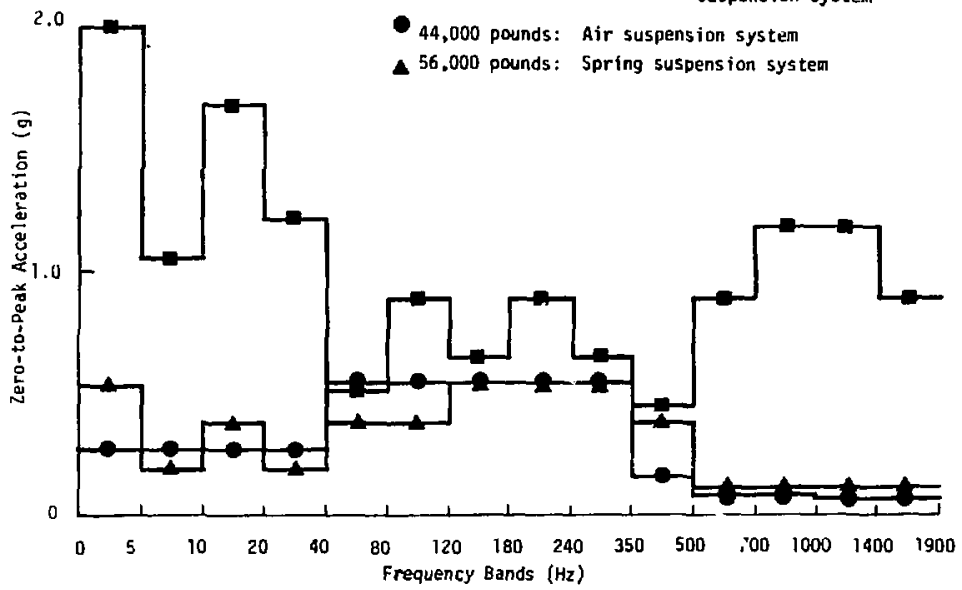

Figure 8. Comparison of Truck Vibration Data, Vertical Axis

Superimposed Shock, Longitudinal Axis

Heavier cargo weight produced a higher amplitude of response in tne longitudinal axis in the $1-\mathrm{Hz}$ to $20-\mathrm{Hz}$ frequency range. These are the frequencies at which suspension systems and tires have the greatest response. Above $80 \mathrm{~Hz}$, the response is lower in amplitude than that for lighter cargo. Comparison of longitudinal axis response spectra obtained fron. test data is showr in Figure 9. 


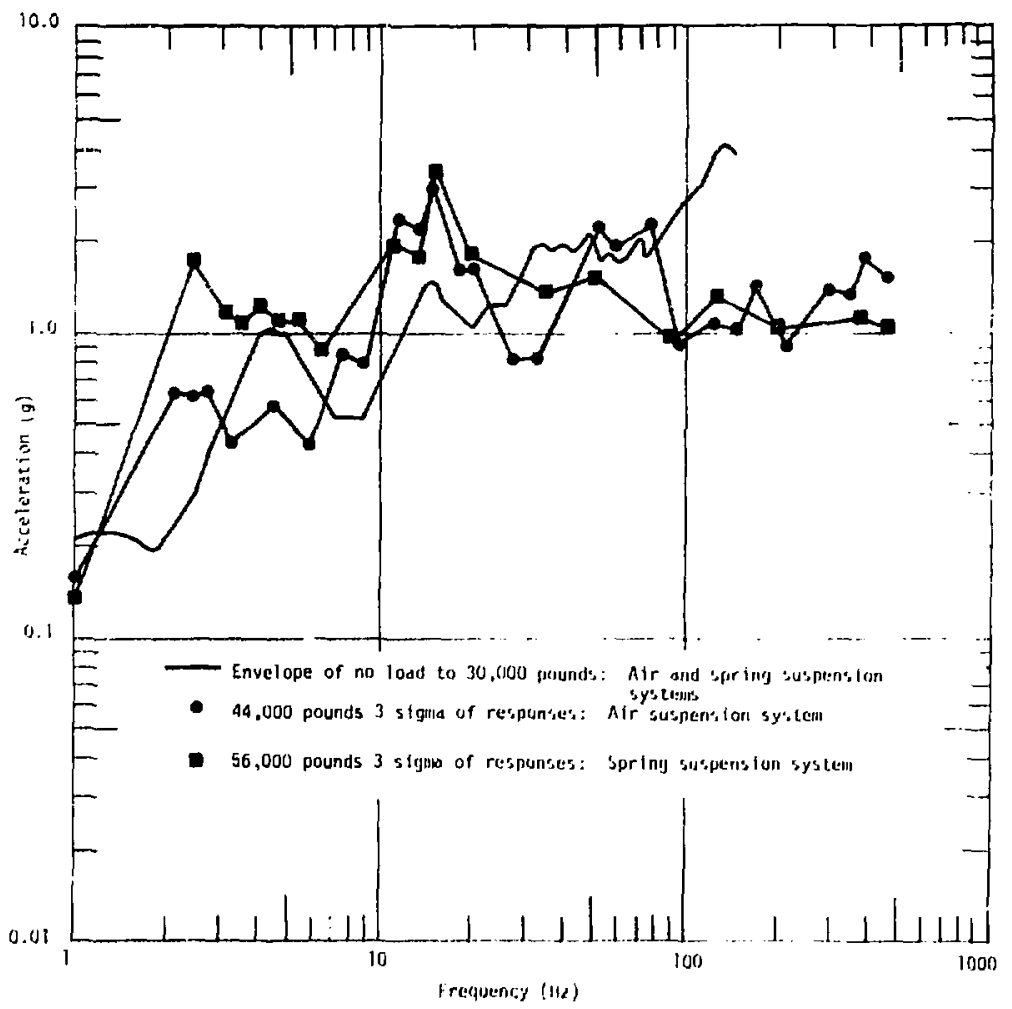

Figure 9. Comparison of Heraponou Eprecera From Truck Dgta 3\% Damping, Langitudinal Axit 


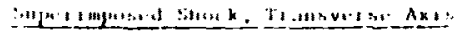

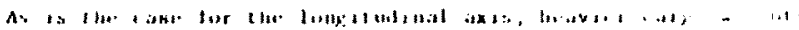

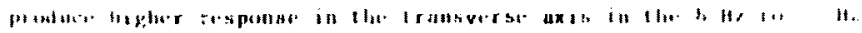
to

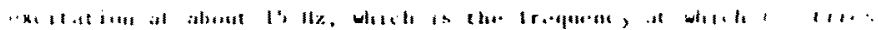

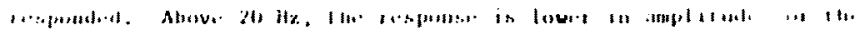

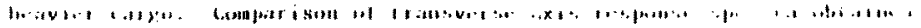

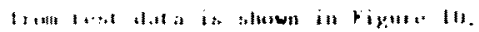

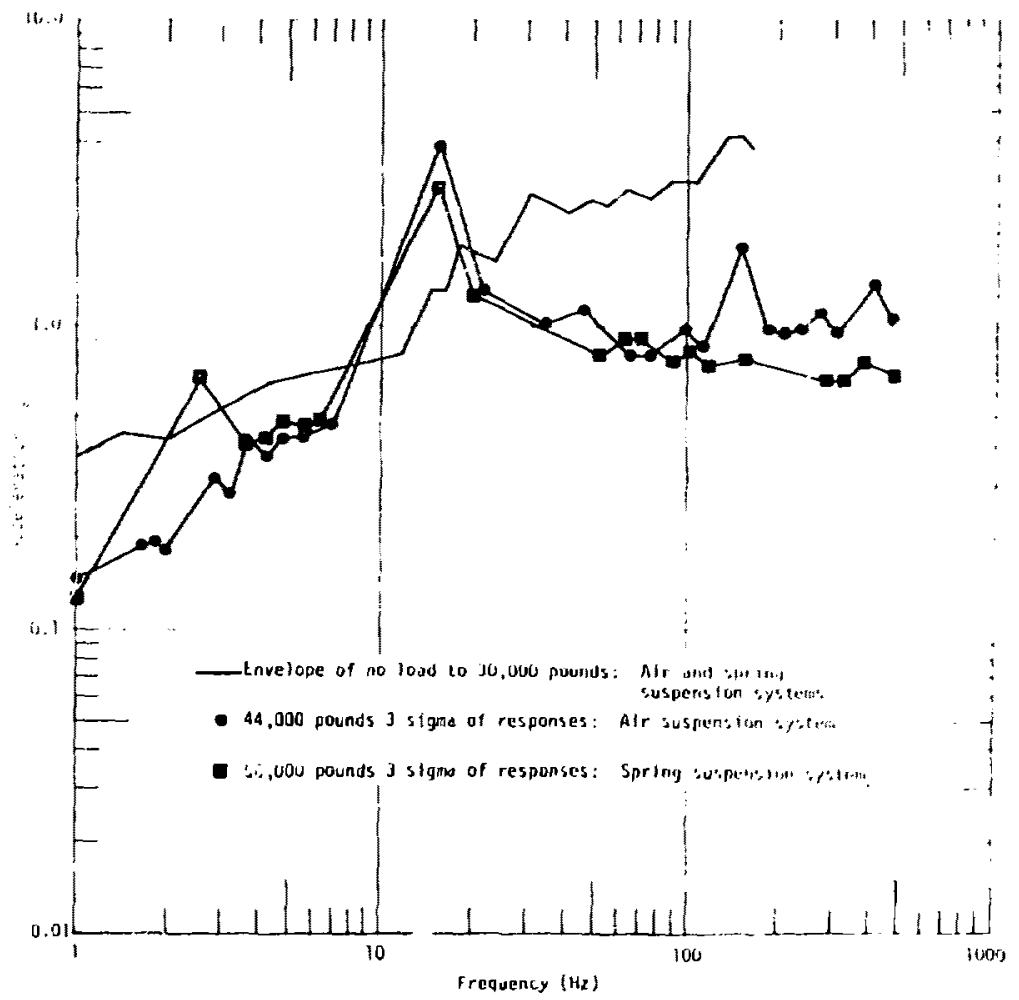

Figure 10. Comparison ot Kesponse spectra frum Truak bula $3 z$ Lamping. Transverge Axis 
Superimposed Shock, Vertical Axis

The response for the vertical axio is lower for heavy cargo in all frequenciea above bout $3 \mathrm{~Hz}$. $A$ in the other two axes, the reaponte caused by suspension syeten and tire hop excitation can be identified below about $20 \mathrm{hz}$. Comparieon of vertical axis reaponse apectra obtoined from lest data is shown in Figure 11 .

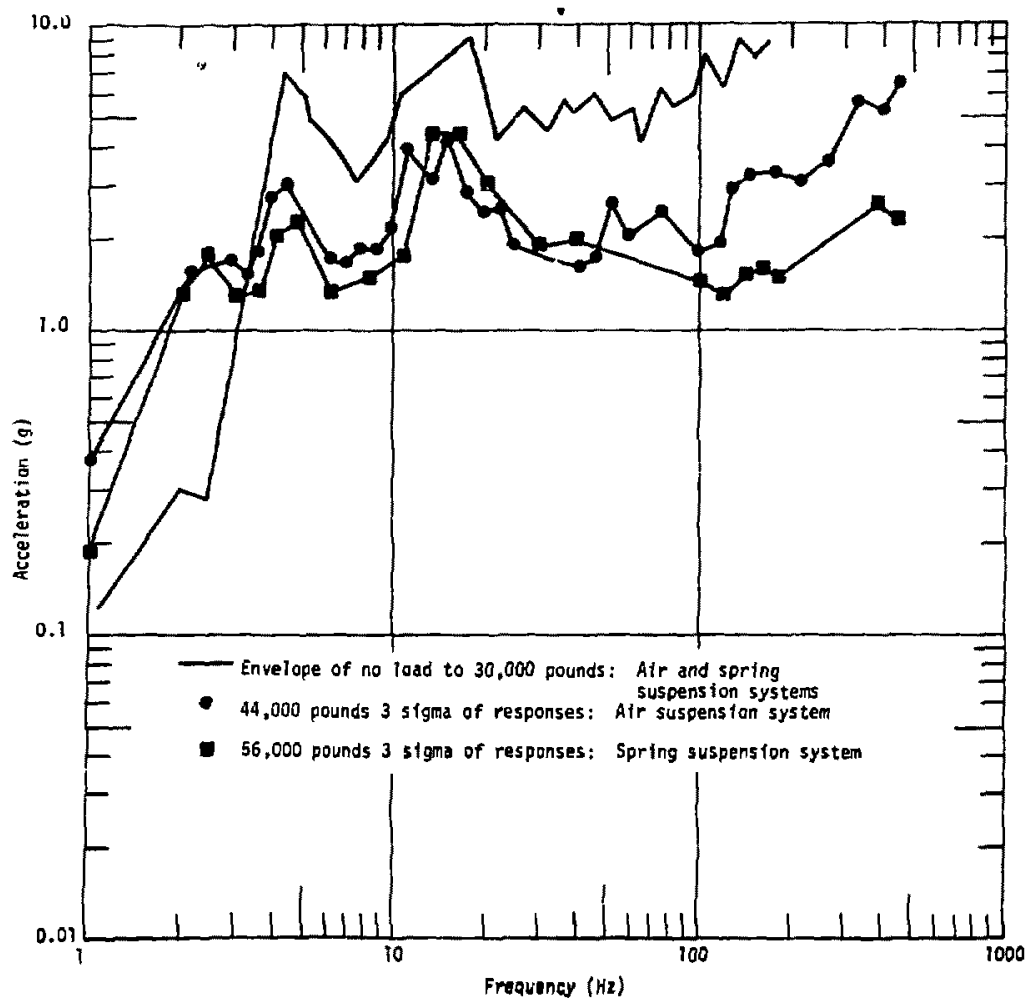

Figure 11. Comparison of Response Spectra From Truck Dat: 35. Damping, Vercical Axis 


\section{Single-Pulse Representation of Superimposed Shock}

Comparison of simple, half-sine input pulses which have response spectra that envelop the response spectra obtained from test data show that for the longitudinal axis, the pulse duration increases with increasing cargo weight and this causes an increased velocity change under the single pulse; this is true fven though the peak acceleration of lhe half-sine pulse decreases with increased cargo weight. The lunger duration of the single pulse results from the enveloping of II igher response at the lower frequencies.

As is the case for the longitudinal axio, the peak acceleration of half-sine input pulses which may represent the shock pulse for the transverse axis decrease with increased cargo weight. In this axis, the pulse duration and the resulting velocity change are greatest for tile $19570 \mathrm{GN}(44,000$ pound) test data.

The simple single half-sine input pulses, which may represent the shock for the vertical axis, change considerably from the light cargo to those for the $195300 \mathrm{~N}$ (44,000-pound) cargo but do not change in anplicude or duration with additional increase in cargo weight. Table IV presents comparisons of simple single half-sine pulses which can be used to represent the shock which is superimposed on and mixed with the vibration during truck transport. 
TABLE IV

Lomparison of Truck Shock Represented by Single Half-Sine Pulses

\begin{tabular}{lcccc}
\multicolumn{1}{c}{ Axis } & $\begin{array}{c}\text { Peak } \\
\text { Acceleration } \\
(\mathrm{g})\end{array}$ & $\begin{array}{c}\text { Duration } \\
(\mathrm{ms})\end{array}$ & $\begin{array}{c}\mathrm{V} \\
(\mathrm{m} / \mathrm{s})\end{array}$ & $\begin{array}{c}\mathrm{V} \\
(\mathrm{ft} / \mathrm{s})\end{array}$ \\
\cline { 5 - 6 } Longitudinol & 2.8 & 20 & 0.3 & 1.1 \\
Iransverge & 2.3 & 19 & 0.3 & 0.9 \\
Vertical & 7.0 & 77 & 3.3 & 10.9
\end{tabular}

\section{(2)}

$\begin{array}{lllll}\text { Langitudinal } & 2.5 & 32 & 0.5 & 1.6 \\ \text { Transverse } & 2.2 & 50 & 0.7 & 2.2 \\ \text { Vertical } & 2.6 & 67 & 1.1 & 3.5\end{array}$

(3)

$\begin{array}{lllll}\text { Longitudinal } & 2.2 & 83 & 1.1 & 3.7 \\ \text { Transverse } & 1.6 & 40 & 0.4 & 1.3 \\ \text { Vertical } & 2.6 & 67 & 1.1 & 3.5\end{array}$

(1) Cargo weight: no load to $133400 \mathrm{~N}(30,000$ pound) spring and aic suspension systems (Reference 1) envelape of data.

(2) Cargo weight: 195 700N (44,000 pounds) air suspension; data from response spectra of three- standarddeviations (Reference 2 ).

(3) Cargo weight: $249100 \mathrm{~N}(56,000$ pounds) spring suspension system; data from response spectra of three st andard-deviations. 
References

1. C. F. Magnuson and L. T. Wilson, Shock and Vibration Environments Ior Large Shipping Containers on Rail Cars and Trucks, SAND76-0427, Sandia Laboratories, Albuquerque, New Mexico, June 1977.

2. C. F. Magnuson, Shock and Vibration Environments for Large Shipping Container During Truck Tranbport (Part I), SAND77-1110, Sandia Laboratories, Albuquerque, New Mexico, September 1977. 